To the Editors:

\section{An outbreak of mumps in Dompe}

A retrospective, descriptive study of an outbreak of mumps in Dompe in 2006, was done by sending selfadministered questionnaires to parents and guardians of cases. One hundred and twenty two mumps cases fulfilling the surveillance case definition for mumps outlined by the Epidemiology Unit of Sri Lanka were included in the study.

The outbreak, spanning from 4 January 2006 to 15 April 2006, followed a pattern of a propagated outbreak (Figure) as expected from the mode of transmission of mumps. The outbreak diminished during the month of April probably due to a reduction in the susceptible population, and the school vacation, which reduced contact.

More males (55\%) were affected. As expected in a country with low rates of mumps immunisation, the majority of those affected were school aged children [1]. (See table 1). The common clinical manifestations are shown in table 2 and 3.

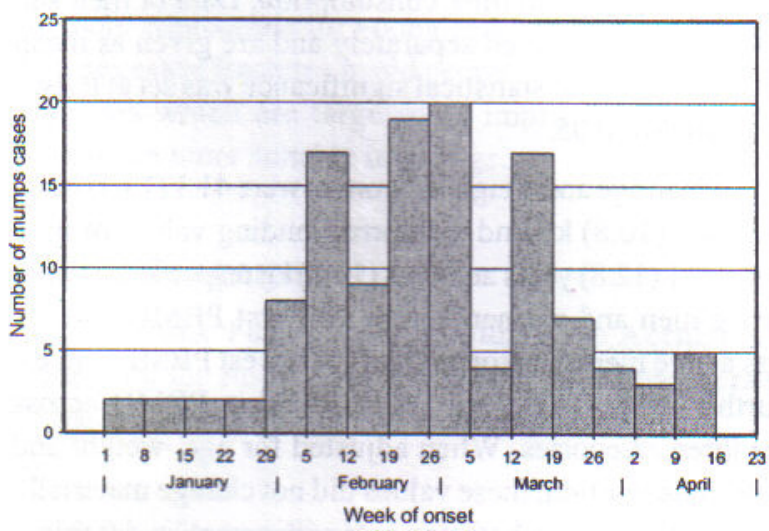

Figure. Weekly number of cases of mumps in Dompe, 4 January - 15 April, 2006 ( $n=122)$.

Table 1. Frequency distribution of mumps cases by age (years) category

\begin{tabular}{lcc}
\hline Age category & Frequency & Percent \\
\hline$<3$ & 4 & 3.3 \\
$3-5$ & 12 & 9.8 \\
$5-8$ & 88 & 72.1 \\
$8-19$ & 11 & 9.0 \\
$>19$ & 7 & 5.7 \\
Total & 122 & 100.0 \\
\hline
\end{tabular}

Table 2. Frequency distribution of symptoms reported by mumps cases

\begin{tabular}{lcr}
\hline Symptom & Frequency & Percent \\
\hline Parotid swelling & 122 & 100.0 \\
Fever & 114 & 93.4 \\
Headache & 84 & 68.9 \\
Earache or pain near earlobes & 76 & 62.3 \\
Myalgia & 57 & 46.7 \\
Submandibular swelling & 46 & 37.7 \\
Vomiting & 33 & 27.0 \\
Sore throat & 5 & 4.1 \\
\hline
\end{tabular}

Table 3. Frequency distribution of first symptom reported by cases

\begin{tabular}{lrr}
\hline First symptom & Frequency & Percent \\
\hline Fever & 50 & 41.0 \\
Earache or pain near earlobe & 28 & 23.0 \\
Swelling around ear & 24 & 19.7 \\
Headache & 12 & 9.8 \\
Myalgia & 6 & 4.9 \\
Sore throat & 2 & 1.6 \\
Total & 122 & 100.0 \\
\hline
\end{tabular}

Since there were no hospitalisations it is unlikely that any cases had meningoencephalitis, myocarditis or pneumonia. However, other complications of mumps were reported, including epigastric pain $(5.7 \%)$, an indication of possible pancreatitis.

Sixty-five percent of respondents knew that mumps was caused by a virus and $71 \%$ indicated droplets as the mode of spread. Various traditional pastes were applied on the swollen parotid glands of $59 \%$ of cases. Animal proteins were withheld from the diet in $66 \%$ of patients. Bathing was also restricted, with an average of 11 days taken for patients to bathe for the first time after the onset of the illness. Primary health care workers should be made aware of these myths and unhealthy practices and encouraged to educate the community.

None of the patients in this study had been vaccinated for mumps. In Sri Lanka, the mumps vaccine is only available in the private sector and is not part of the 


\section{Research letters}

national immunisation program. Countries that have included the two-dose mumps vaccination in their national immunisation programme and achieved high coverage rates have reported a case reduction greater than $97 \%$ [2].

Our study is useful to give some indication of the clinical course and disease burden of mumps in Sri Lanka and to help evaluate the need for widespread mumps immunization.

\section{References}

1. WHO. Mumps virus vaccines. Weekly Epidemiological Record 2001; 76: 345-56.

2. Galazka AM, Robertson SE, Kraigher A. Mumps and mumps vaccine: a global review. Bulletin of the World Health Organization 1999; 7: 3-14.

P Palihawadana, Epidemiologist, Epidemiology Unit, Ministry of Health, ILK Jayaratne, Postgraduate Trainee, Department of Community Medicine, Faculty of Medicine, University of Colombo, and N Wijemunige, Research Assistant, Epidemiology Unit, Ministry of Health, Sri Lanka.

Correspondence: PP, e-mail: <paba@health.gov.lk>. Received 10 November 2006, and revised version accepted 6 February 2007. Financial support was from the Epidemiology Unit, Ministry of Health, Sri Lanka. Conflict of interest:
none declared. 